\title{
Estudo da retina de coelhos após injeção intravítrea de bupivacaína
}

\author{
Retinal toxicity effects of intraocular injection of bupivacaine in rabbits
}

\author{
Hermelino Lopes de Oliveira Neto ${ }^{1}$ \\ Michel Eid Farah ${ }^{2}$ \\ Ricardo Luiz Smith ${ }^{3}$ \\ Maria Cristina Martins ${ }^{4}$
}

\section{RESUMO}

Objetivo: Avaliar alterações morfológicas causadas por injeção intravítrea de bupivacaína, anestésico local de ação prolongada muito utilizado em bloqueios regionais oculares, na retina de coelhos albinos. Métodos: A droga na concentração de $0,75 \%$ em $0,1 \mathrm{~mL}$ foi injetada na cavidade vítrea próximo a retina num olho, enquanto solução salina balanceada em igual volume foi injetada no olho contralateral (controle). Foram realizadas oftalmoscopias indiretas antes, durante, imediatamente após e nos períodos de $1 \mathrm{~h}, 24 \mathrm{~h}$ e $72 \mathrm{~h}$, microscopias de luz e eletrônica de transmissão em 24 e 72 horas depois da administração do anestésico. Resultados: No exame oftalmoscópico imediatamente após a injeção de bupivacaína, encontrouse em todos os casos a retina com aspecto esbranquiçado próximo ao local da injeção, fenômeno atribuído à presença de depressão alastrante, também observada (com menor freqüência e intensidade) nos olhos do grupo controle. Outras alterações encontradas incluíram: edema de retina, 6 (60\%); área de condensação vítrea, 5 (50\%); e pulso arterial de papila, 2 $(20 \%)$. Conclusões: Injeção intravítrea de bupivacaína em concentração de $0,75 \%$ (usada para anestesia local retrobulbar, peribulbar ou outra técnica em cirurgias oculares prolongadas) não desencadeou alterações morfológicas quando estudadas pela microscopia de luz; porém desencadeou alterações sugestivas de edema discreto nas células horizontais da retina de coelhos albinos, estudados com microscopia eletrônica de transmissão, nos períodos de 24 e 72 horas.

Descritores: Retina; Bupivacaína/efeitos adversos; Bupivacaína/toxidade; Toxidade de drogas; Coelhos

\section{INTRODUÇÃO}

A anestesia local é um método seguro e eficiente para uso ambulatorial ou hospitalar. Embora tenha surgido na época posterior à anestesia geral, vem sendo cada vez mais divulgada e ganhando um número crescente de indicações $^{(1)}$.

Os agentes anestésicos locais mais utilizados em oftalmologia são a proparacaína, tetracaína, lidocaína e a bupivacaína ${ }^{(2)}$. A bupivacaína (Marcaína $^{\circledR}$ ) é um anestésico local do grupo amida e primeiramente sintetizada em $1957^{(3)}$. Esta droga é caracterizada por ter ação longa, tanto no período de latência quanto no tempo de efeito, sendo a intensidade de analgesia quatro vezes maior que a da lidocaína. É muito utilizada em anestesias regionais oculares ${ }^{(4)}$, principalmente em procedimentos que requerem efeito anestésico duradouro, como as cirurgias vítreo-retinianas ${ }^{(5)}$.

$\mathrm{O}$ risco de perfuração escleral durante a administração de anestesia retrobulbar $(\mathrm{RB})$ ou peribulbar $(\mathrm{PB})$ com lidocaína ou bupivacaína foi des- 
crito na literatura, sendo baixa sua taxa em ambas as técnicas ${ }^{(6-7)}$. A maior incidência dessa complicação ocorre principalmente em olhos míopes, associados a fatores predisponentes para perfuração do bulbo ocular, tais como aumento do comprimento axial, afinamento escleral, estafiloma posterior e explante escleral pré-existente pós-cirurgia de descolamento de retina ${ }^{(6)}$.

Injeção intra-ocular acidental de bupivacaína é mais freqüente do que injeção intra-ocular de agentes anestésicos como a lidocaína, utilizada geralmente em cirurgias de curta duração ${ }^{(7)}$.

Porém, nenhum caso de toxicidade retiniana por injeção acidental de bupivacaína foi relatado, e apenas dois estudos experimentais em coelhos sobre os efeitos locais dessa droga na retina foram descritos ${ }^{(7-8)}$.

\section{OBJETIVO}

Este trabalho tem como objetivo estudar a morfologia da retina de coelhos após injeção intravítrea de bupivacaína, utilizando-se oftalmoscopia para controle clínico e microscopias óptica de luz e eletrônica de transmissão para análise histopatológica.

\section{MÉTODOS}

\section{Animais}

Dez coelhos albinos, pesando 3,0 a 4,0 Kg cada, provenientes do Biotério Central da Universidade Federal de São Paulo (UNIFESP) foram usados neste estudo. Os experimentos seguiram as normas da declaração de Helsinque ${ }^{(9)}$.

\section{Procedimento}

Os coelhos foram submetidos à anestesia geral com injeção intramuscular de cloridrato de ketamina $(20 \mathrm{mg} / \mathrm{Kg}$ de peso). As pupilas foram dilatadas previamente com colírio de tropicamida a $1 \%$. O exame de fundo de olho, seguido da injeção intravítrea, foi realizado após midríase completa em todos os olhos antes, durante e imediatamente após a administração do anestésico, e repetido após uma, 24 e 72 horas da injeção, observando-se as reações clínicas oftalmoscópicas relativas à injeção e classificando-as em leve, moderada ou intensa, quando presentes. Os animais foram divididos em dois grupos para exame histológico (grupo I e II), sendo um sacrificado em 24 horas e outro em 72 horas.

\section{Injeção intravítrea}

Após anestesia geral e tópica com colírio de cloridrato de proximetacaína a $0,5 \%$, realizou-se a injeção intravítrea com agulha calibre 25 montada em seringa de $1,0 \mathrm{ml}$ (de tuberculina). A agulha foi introduzida $2 \mathrm{~mm}$ posteriormente ao limbo, avançando-se na cavidade vítrea em direção ao disco óptico, próximo à retina e abaixo das fibras radiadas, sob monitorização concomitante com oftalmoscopia (Figura 1). Foi injetado

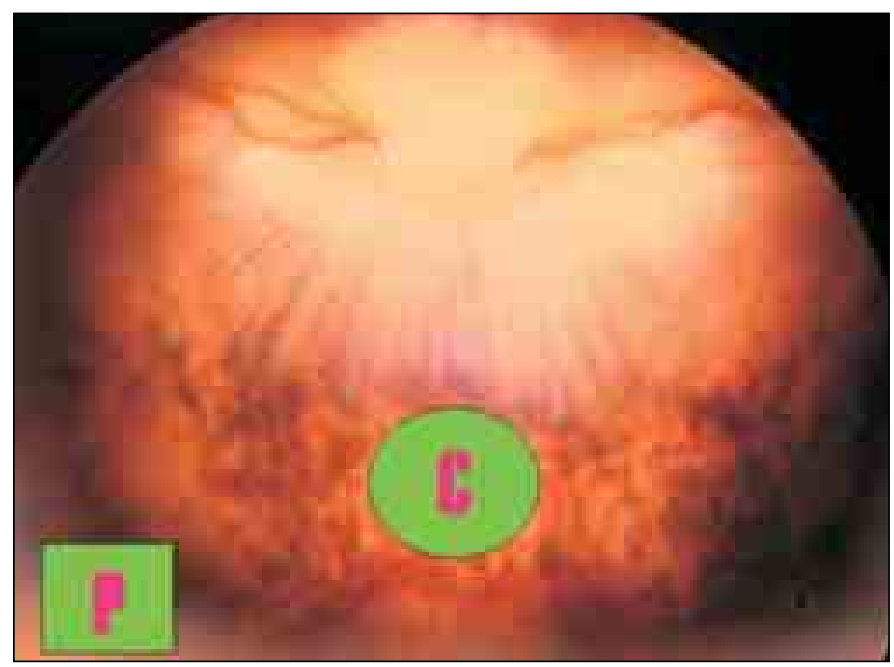

Figura 1 - Retinografia colorida da retina de coelho mostrando o local da injeção $(C)$ de bupivacaína $0,75 \%$ e a região periférica $(P)$, processados para estudo histopatológico com microscopias de luz e eletrônica de transmissão

lentamente $0,1 \mathrm{ml}$ de Bupivacaína (Marcaína ${ }^{\circledR}$ ) (Astra, Canadá) no corpo vítreo (olho experimental). O mesmo volume de solução salina balanceada (BSS PLUS ${ }^{\oplus}$ ) foi injetado de maneira similar no olho contralateral (controle).

\section{Exame histológico}

Dez olhos (5 coelhos) foram enucleados após 24 horas (Grupo I) e o restante após 72 horas (Grupo II) da injeção intravítrea, sendo para cada grupo 6 olhos submetidos à análise histopatológica em microscopia de luz ( 3 contendo bupivacaína intra-ocular e 3 com solução salina balanceada) e 4 olhos submetidos à análise histopatológica em microscopia eletrônica de transmissão ( 2 contendo bupivacaína e 2 solução salina balanceada). Retirou-se material do local da injeção e outro em área periférica (Figura 1), sendo processado para estudo histopatológico com microscopia de luz e eletrônica de transmissão.

\section{RESULTADOS}

\section{Oftalmoscopia}

a) antes da injeção

A oftalmoscopia binocular indireta realizada antes da injeção intravítrea não apresentou alterações em nenhum dos olhos examinados. Não houve intercorrência durante os procedimentos em nenhum dos animais.

b) imediatamente após a injeção

A oftalmoscopia binocular indireta realizada após o experimento revelou alterações em todos os olhos. (Tabela 1)

No exame oftalmoscópico realizado imediatamente após a injeção de bupivacaína $(\mathrm{N}=10)$, encontrou-se em todos os casos a retina com aspecto esbranquiçado de intensidade variável: dois (20\%) leve, seis $(60 \%)$ moderado e dois $(20 \%)$ 


\begin{tabular}{|c|c|c|c|c|}
\hline \multirow[b]{2}{*}{ Alterações fundoscópicas } & \multicolumn{2}{|c|}{ Bupivacaína } & \multicolumn{2}{|c|}{ SSB } \\
\hline & $n^{\circ}$ & $\%$ & $\mathbf{n}^{\circ}$ & $\%$ \\
\hline Período Imediato & 10 & $100 \%$ & 07 & $70 \%$ \\
\hline \multicolumn{5}{|l|}{ Retina esbranquiçada } \\
\hline Leve & 02 & $2 \%$ & 07 & $70 \%$ \\
\hline Moderada & 06 & $60 \%$ & - & $0 \%$ \\
\hline Intensa & 02 & $2 \%$ & - & $0 \%$ \\
\hline Área de condensação vítrea & 05 & $50 \%$ & 01 & $10 \%$ \\
\hline Edema de retina & 06 & $60 \%$ & 02 & $20 \%$ \\
\hline Pulso de vasos da papila & 02 & $20 \%$ & - & $0 \%$ \\
\hline \multicolumn{5}{|l|}{ Período de $1 \mathrm{~h}$} \\
\hline Retina esbranquiçada & - & $0 \%$ & - & $0 \%$ \\
\hline Área de condensação vítrea & 06 & $60 \%$ & 01 & $10 \%$ \\
\hline Edema de retina & 08 & $80 \%$ & 02 & $20 \%$ \\
\hline Descolamento seroso de retina & 02 & $20 \%$ & - & $0 \%$ \\
\hline \multicolumn{5}{|l|}{ Período de 24 h } \\
\hline Área de condensação vítrea & 03 & $30 \%$ & 01 & $10 \%$ \\
\hline Edema de retina & - & $0 \%$ & - & $0 \%$ \\
\hline Descolamento seroso de retina & 02 & $20 \%$ & - & $0 \%$ \\
\hline \multicolumn{5}{|l|}{ Período de $72 \mathrm{~h}$} \\
\hline Área de condensação vítrea & 03 & $30 \%$ & 01 & $10 \%$ \\
\hline Total & 10 & $100 \%$ & 10 & $100 \%$ \\
\hline
\end{tabular}

intenso. Outras alterações encontradas, incluíram: seis (60\%), edema de retina; cinco (50\%), área de condensação vítrea; e dois (20\%) pulso arterial de disco óptico.

Nos olhos contralaterais submetidos à injeção de solução salina balanceada $(\mathrm{N}=10)$, encontrou-se a retina com aspecto esbranquiçado em sete $(70 \%)$, sendo todos de intensidade leve e próximo ao local da injeção. Outras alterações incluíram: dois $(20 \%)$, edema de retina; e um caso $(10 \%)$ de área de condensação vítrea.

\section{c) Após uma hora}

A retina não se apresentou esbranquiçada em nenhum dos olhos, uma hora após a injeção intravítrea do anestésico. Nos olhos submetidos à injeção intravítrea de bupivacaína, oito olhos (80\%) tinham edema de retina, seis $(60 \%)$ área de condensação vítrea e dois (20\%) apresentavam descolamento seroso de retina. No grupo controle, poucas alterações foram encontradas: edema de retina, dois (20\%) e anel vítreo em um (10\%).

Em nenhum dos olhos foi encontrado rotura ou descolamento regmatogênico de retina.

d) Após 24 e 72 horas

Foram observados à oftalmoscopia, nos olhos submetidos à injeção intravítrea de bupivacaína, área de condensação vítrea em três $(30 \%)$ e descolamento seroso de retina em dois $(20 \%)$. No grupo controle, observou-se somente área de condensação vítrea em um (10\%).

\section{Microscopia de luz}

Em todas as amostras estudadas sob microscopia óptica de luz foi observada a estrutura retiniana preservada. Camadas de cones e bastonetes, nuclear externa, plexiforme externa, nuclear interna, plexiforme interna, de células ganglionares e camada de fibras nervosas estavam intactas.

Observou-se em todas as amostras a ocorrência de células grandes de núcleo redondo, e citoplasma claro e abundante, podendo ser considerado cromofóbico. Essas células são encontradas na camada nuclear interna, por vezes projetando-se em direção à camada plexiforme externa e, muitas vezes, o volume de uma única célula equivale a toda a espessura da camada nuclear interna. (Figura 2)

\section{Microscopia eletrônica de transmissão \\ Grupo I}

O vítreo, a interface vítreo-retiniana e a retina não apresentaram alterações significativas quanto à ultra-estrutura.

A diferença notada ocorreu na camada nuclear interna, mais precisamente nas células horizontais. Essas células apresentaram aspecto sugestivo de edema, citoplasma com eletrondensidade diminuída, mitocôndrias dilatadas e com poucas cristas no interior e cisternas do retículo endoplasmático dilatadas. $\mathrm{O}$ edema estava presente nos prolongamentos das células horizontais e terminações nervosas incluídas nas sinapses invaginadas dos fotorreceptores, com citoplasma rarefeito (Figura 3). O aspecto de edema foi observado no fragmento de retina da área periférica ao local da injeção intravítrea, não havendo diferenças entre as duas regiões.

\section{Grupo II}

As retinas examinadas após 72 horas não mostraram diferenças evidentes em relação às do grupo I. As camadas do epitélio pigmentado e dos fotorreceptores não apresentaram alterações entre as regiões, central e periférica, onde os fragmentos de retina foram obtidos.

$\mathrm{O}$ aspecto sugestivo de edema foi observado nesse grupo. A camada plexiforme externa apresentou rarefação do citoplasma dos prolongamentos das células horizontais, inclusive no interior das sinapses invaginadas. As células horizontais mostraram o

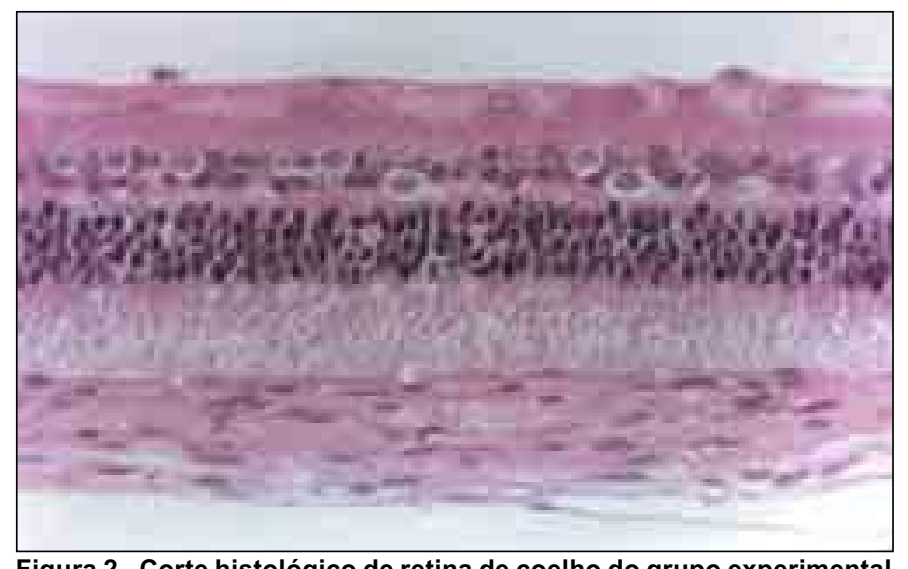

Figura 2 - Corte histológico de retina de coelho do grupo experimental (bupivacaína), 24h. Estrutura normal. (Hematoxilina \& Eosina, X 400) 


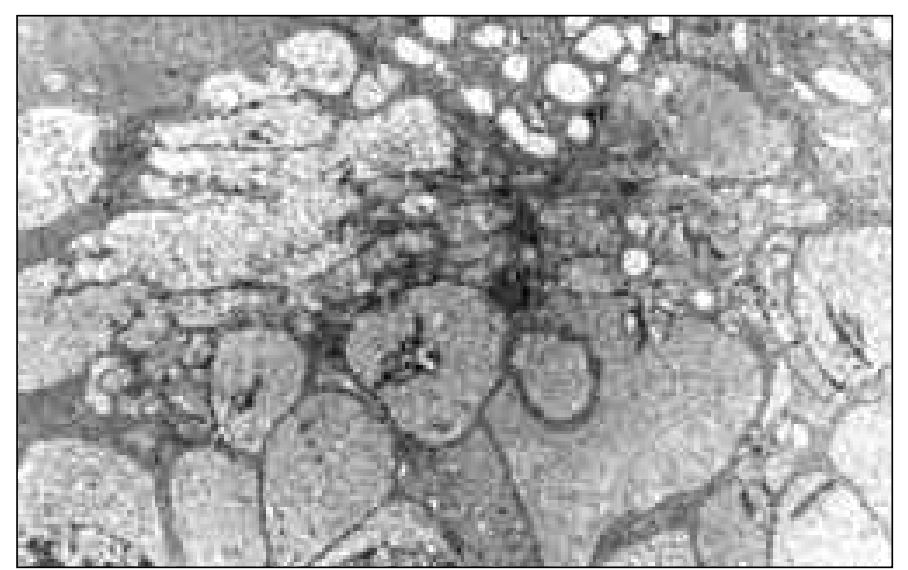

Figura 3 - Microscopia eletrônica de retina do grupo experimental, 24h, local da injeção, camadas nuclear e plexiforme externas. Processos de células horizontais com citoplasma rarefeito. (X 9.760)

citoplasma rarefeito, corpos multivesiculares e mitocôndrias vacuolizadas com remanescentes de cristas (Figuras 4).

\section{Grupo Controle}

A retina não apresentou alterações significativas à ultraestrutura. $\mathrm{O}$ epitélio pigmentado e as camadas da retina neurosensorial não mostraram alterações significativas (Figura 5). Não foram encontradas alterações no vítreo ou células na região da interface vítreo-retiniana. A camada nuclear interna, mais precisamente células horizontais, estavam com a estrutura preservada.

\section{DISCUSSÃO}

No presente estudo, foi utilizada a concentração de bupivacaína a $0,75 \%$ pelo uso freqüente desta solução em procedimentos que requerem analgesia de longa duração, como nas cirurgias vítreo-retinianas $^{(5)}$, e pela maior predisposição des-

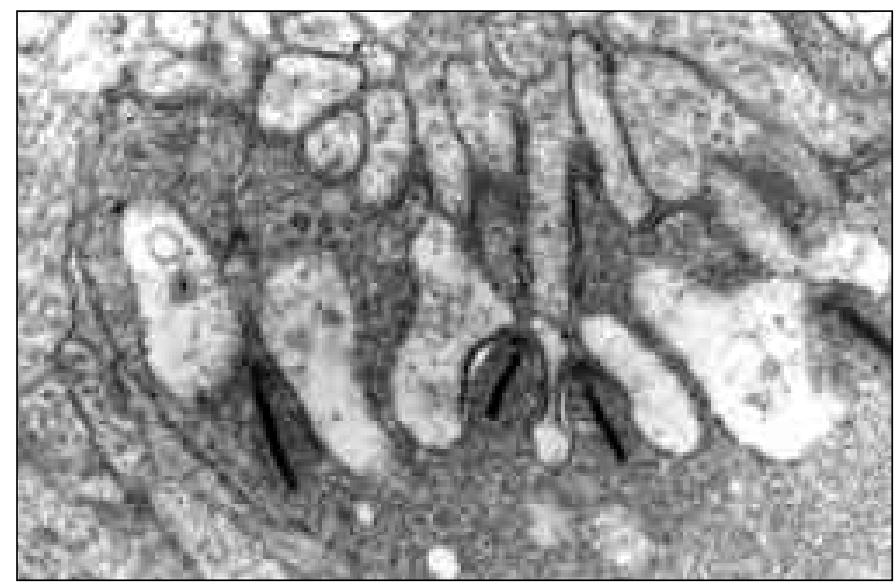

Figura 4 - Microscopia eletrônica de retina do grupo experimental, $72 \mathrm{~h}$, local da injeção, camada plexiforme externa com sinapses invaginadas apresentando processos das células horizontais com citoplasma rarefeito em torno das lamelas sinápticas. ( $X$ 44.800)

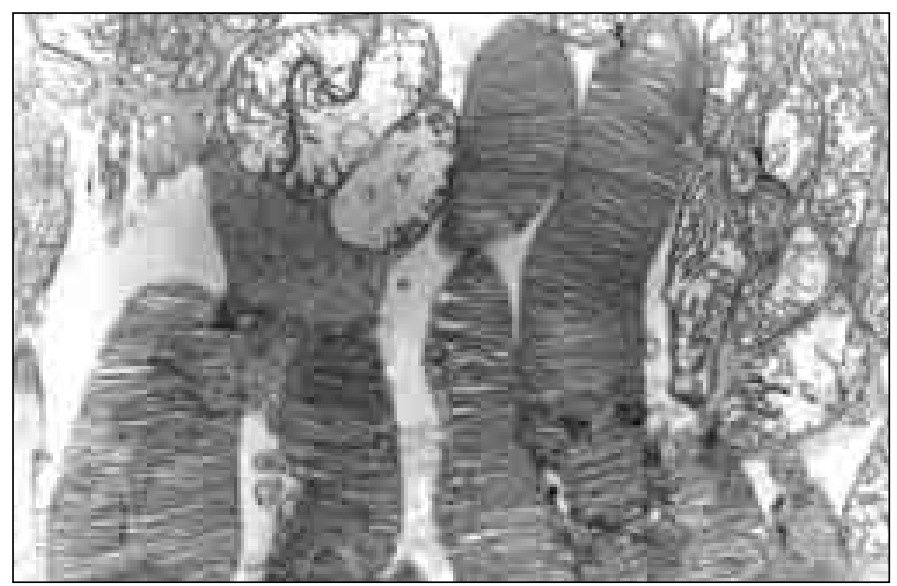

Figura 5 - Microscopia eletrônica de retina do grupo controle; segmentos externos e internos de fotorreceptores. (X 14.400)

tes casos à perfuração acidental por agulha ${ }^{(6)} \mathrm{e}$ injeção intraocular acidental no segmento posterior do bulbo ocular ${ }^{(7)}$.

$\mathrm{O}$ achado oftalmoscópico de retina esbranquiçada deve ser atribuído à presença do fenômeno de depressão alastrante. Esse fenômeno foi inicialmente descrito em $1944^{(10)}$ sendo identificado uma resposta no córtex cerebral a estímulos locais e caracterizada por depressão prolongada da atividade elétrica espontânea, que se propaga em todas as direções a partir do ponto de origem. A depressão alastrante é um fenômeno reversível e, após um período de aproximadamente 20 minutos, o tecido encontra-se recuperado, podendo-se provocar outra depressão alastrante. Na retina, este fenômeno foi identificado inicialmente em anfíbios ${ }^{(1)}$ e depois confirmado por outros autores em retina de animais vertebrados, inclusive mamíferos ${ }^{(12)}$.

Neste estudo, interpretamos como depressão alastrante a observação oftalmoscópica de retina esbranquiçada, detectada com intensidade variável, transitória e reversível. O estímulo que provocou o fenômeno foi interpretado como mecânico, por ter afetado ambos os olhos, e também químico, por ter maior intensidade ou maior freqüência no olho injetado com bupivacaína.

Alguns autores ${ }^{(13)}$ observaram lesões morfológicas na retina de coelhos, submetidos à injeção intravítrea de $10 \mathrm{mg}(0,1 \mathrm{ml})$ de lidocaína, tais como afinamento e perda das camadas estruturais no local próximo da injeção. Comparando-se com as áreas correspondentes no olho controle que recebeu solução salina, não foi observada alteração histopatológica em áreas distantes (cerca de $15 \mathrm{~mm}$ do local da injeção). Os efeitos de outra droga estudada por esses mesmos autores, bupivacaína na dosagem de $0,5 \mathrm{mg}(0,1 \mathrm{ml})$, não produziu nenhuma anormalidade morfológica nas retinas de coelhos pigmentados ou albinos.

Neste estudo, não foram encontradas alterações morfológicas na retina de coelhos albinos pela microscopia de luz utilizando injeção intravítrea de bupivacaína, coincidindo com este estudo ${ }^{(13)}$ que avaliou os efeitos tóxicos da lidocaína a $1 \%$ e $2 \%$ e bupivacaína $0,5 \%$ em coelhos albinos e pigmentados. Resultados semelhantes foram obtidos em outros estudos ${ }^{(8)}$ 
com injeções intravítrea de lidocaína a $0,5 \%, 1,0 \%$ e $2 \%$ e bupivacaína a $0,5 \%$ e $0,75 \%$ em coelhos albinos. Porém, nenhum desses autores realizou estudo histopatológico em microscopia eletrônica.

O achado pela microscopia de luz de células grandes de núcleo redondo e citoplasma claro e abundante, localizados na camada nuclear interna e plexiforme externa são normalmente encontradas na retina de coelho, única espécie de mamíferos a possuí-las. Estas células poderiam representar células bipolares ou horizontais gigantes, devido à posição em que se encontram, ou ainda astrócitos gigantes ${ }^{(14)}$.

O encontro de edema, pela microscopia eletrônica, evidente nas células horizontais não deve ser atribuído à depressão alastrante, pois não ocorreu nos olhos controle.

Neste estudo, não foram encontradas alterações morfológicas significativas na retina de coelhos albinos pela microscopia de luz e eletrônica de transmissão que possam sugerir qualquer toxicidade retiniana conseqüente a injeção intravítrea de bupivacaína a $0,75 \%$. Porém, a toxicidade no vítreo e retina não estão relacionadas somente à dosagem da droga. Os efeitos da injeção vítrea dependem também de outros fatores como local da injeção, padrão de difusão e características fisiológicas, vasculares e hidrodinâmicas, particulares de cada olho e de cada espécie animal ${ }^{(15)}$, não analisado neste estudo. Os estudos podem ser pesquisados no futuro, através de marcadores radioativos e testes funcionais da retina por meio do eletrorretinograma, além de pesquisas com dosagens maiores e combinações de anestésicos.

\section{CONCLUSÃO}

Injeção intravítrea de bupivacaína em concentração de 0,75\% (anestésico usado para anestesia local retrobulbar, peribulbar ou outra técnica em cirurgias oculares prolongadas) não desencadeou alterações morfológicas quando estudadas pela microscopia de luz; porém desencadeou alterações sugestivas de edema discreto nas células horizontais da retina de coelhos albinos, estudados com microscopia eletrônica de transmissão após 24 e 72 horas da injeção.

\section{ABSTRACT}

Purpose: To evaluate morphologic alterations caused by intravitreous injection of bupivacaine, a long-term local anesthetic agent much used in ocular regional blockades, in the retina of albino rabbits. Methods: The drug was injected at a $0.75 \%$ in $0.1 \mathrm{ml}$ concentration into the vitreous, close to the retina in one eye, while an equal volume of balanced saline solution was injected into the other eye (control), with indirect ophthalmos- copy performed before, during and immediately after the procedure and at 1hour, 24 hours and 72 hours; both light and electron microscopy were performed at 24 and 72 hours after administration of the anesthetic agent. Results: Immediately following the injection of bupivacaine, ophthalmoscopy revealed the retina to have in all cases a whitened aspect close to the injection site, a phenomenon attributed to the presence of spreading depression, which was also found (at less frequency and intensity), in the control eyes. Further found alterations included: retina edema, $6(60 \%)$; area of vitreous condensation, 5 (50\%); and papilla pulse, 2 (20\%). Conclusions: Intravitreous injection of bupivacaine at $0.75 \%$ concentration (used for retrobulbar, peribulbar local anesthesia or a different technique in extended eye surgeries) triggered no morphological alterations when studied by light microscopy; the injection however did trigger mild edema-suggesting alterations in the horizontal cells of the retina of albino rabbits, studied by electron microscopy within the 24 and 72-hour periods.

Keywords: Retina; Bupivacaine/adverse effects; Bupivacaine/toxicity; Drug toxicity; Rabbits

\section{REFERÊNCIAS}

1. Carvalho JCA, Mathias RS. Farmacologia dos anestésicos locais. In: Manica JT. Anestesiologia: princípios e técnicas. 2.ed. Porto Alegre: Artes Médicas;1997. p.332-40.

2. Cangiani LM. Anestesia em oftalmologia. In: Manica JT. Anestesiologia: princípios e técnicas. 2.ed. Porto Alegre: Artes Médicas;1997. p.608-15.

3. Ekenstam B, Egner B, Pettersson G. N-alkyl pyrolidine and N-alkyl piperidine carboxylic acid amides. Acta Chem Scand 1957;11:1183.

4. Carolan JÁ, Cerasoli JR Houle TV. Bupivacaine in retrobulbar anesthesia. Ann Ophthalmol 1974;6:843-7.

5. Holekamp TL, Arribas NP, Boniuk I. Bupivacaine anesthesia in retinal detachment surgery. Arch Ophthalmol 1979;97:109-11.

6. Ramsay RC, Knobloch WH. Ocular perforation following retrobulbar anesthesia for retinal detachment surgery. Am J Ophthalmol 1978;86:61-4.

7. Kimble JA, Morris RE, Witherspoon CD, Feist RM. Globe perforation from peribulbar injection. Arch Ophthalmol 1987;105:749.

8. Liang C, Peyman GA, Sun G. Toxicity of intraocular lidocaine and bupivacaine. Am J Ophthalmol 1998;125:191-6.

9. World Medical Association. Declaration of Helsinki: recommendations guiding medical doctors in biomedical research involving human subjects. IN: ARVO. The Association for Research in Vision and Ophthalmology [abstract]. Annual Meeting, Fort Lauderdale, Florida; May 11-16; 1996.

10. Leão AAP. Spreading depression of activity in cerebral cortex. J Neurophysiol 1944;7:359-90

11. Gouras P. Spreading depression in amphibian retina. Am J Physiol 1958; 195:28-32.

12. Marques HÁ. Depressão alastrante em retina isolada de mamíferos. Rio de Janeiro, 1982. [Tese de Doutorado]. Rio de Janeiro: Universidade Federal do Rio de Janeiro. Instituto de Biofísica; 1982.

13. Zemel E, Loewenstein A, Lazar M, Perlman I. The effects of lidocaine and bupivacaine on the rabbit retina. Doc Ophthalmol 1995;90:189-99.

14. Rince JH, McConnel DG. Retina and Optic Nerve. In: Prince JH. The rabbit in eye research. Springfield: Charles C. Thomas; 1964. p.385-431.

15. Marmor MF. Retinal detachment from hyperosmotic intravitreal injection. Invest Ophthalmol Visual Sci 1979;18:1237-44. 